\title{
Refeeding Enhances Intestinal Repair during an Acute Enteritis in Infant Rabbits Subjected to Protein-Energy Malnutrition
}

\author{
J. DECKER BUTZNER AND D. GRANT GALL
}

Gastrointestinal Research Group, The University of Calgary, Alberta, Canada T2N 4NI

\begin{abstract}
We examined the effects of refeeding during an acute bacterial enteritis on small intestinal repair in infant rabbits subjected to protein-energy malnutrition and in noninfected and infected dietary controls. Malnutrition was induced by litter expansion at $7 \mathrm{~d}$ of age. Randomly selected litters from both dietary groups were infected on d 17 with Yersinia enterocolotica. Inflammation and intestinal damage were observed in the jejunum and ileum at the "acute stage" of infection in 23-d-old animals from both dietary groups, as evidenced by an inflammatory infiltrate, blunted villi, and reduced disaccharidase activities. In addition, ileal glucose-stimulated $\mathrm{Na}^{+}$absorption was depressed. On d 24, a 7-d period of ad libitum refeeding of breast milk and rabbit feed was initiated in randomly selected litters of infected-malnourished animals and all dietary controls. Mucosal repair was nearly complete at 31 d of age in infected dietary controls and in the infectedmalnourished animals that were refed, as demonstrated by the recovery of segmental mucosal mass and ileal glucosestimulated $\mathrm{Na}^{+}$transport in association with the resolution of inflammation and diarrhea. Only mucosal disaccharidase activities remain depressed. In contrast, in 31-d-old infected-malnourished animals subjected to ongoing nutrient deprivation, severe intestinal damage persisted as evidenced by increased mortality, ongoing intestinal inflammation, mucosal hypoplasia, depressed disaccharidase activities, and reduced glucose-stimulated $\mathrm{Na}^{+}$transport. We conclude that a refeeding regimen introduced during an acute bacterial enteritis is well tolerated and promotes recovery of intestinal mass, structure, and function in malnourished infant rabbits and dietary controls. (Pediatr Res 29: 594-600, 1991)
\end{abstract}

\section{Abbreviations}

PD, transepithelial potential difference

$\mathrm{I}_{\mathrm{sc}}$, short-circuit current

$\mathbf{J}_{\mathrm{ms}}$, mucosal to serosal sodium flux

$\mathbf{J}_{\mathrm{sm}}$, serosal to mucosal sodium flux

$\mathbf{J}_{\text {net }}$, net sodium flux

Recent clinical studies have demonstrated that the duration of an acute diarrheal illness is prolonged in the malnourished infant

Received September 24, 1990; accepted January 24, 1991

Correspondence and reprint requests: J. Decker Butzner, M.D., Department of Pediatrics, The University of Calgary, Health Sciences Centre, 3330 Hospital Drive N.W., Calgary, Alberta, T2N 4NI, Canada.

Supported by the Intestinal Disease Research Unit, the Medical Research Council of Canada, and the Canadian Foundation for lleitis and Colitis. J.D.B. is the recipient of a Clinical Investigatorship award from the Alberta Heritage Foundation for Medical Research.
(1-3). Investigators have also shown that during an acute enteric illness, early nutritional intervention of nourished infants is well tolerated. A rapid return to adequate nutritional intake results in reduced weight loss but does not alter the duration or severity of the diarrheal illness (4-13). Early refeeding also may prevent fatal hypoglycemia, a recently recognized complication of acute diarrheal illness in infants (14). However, the effects of intensive oral nutritional support on the intestinal repair of the acute damage caused by an enteric infection in well-nourished and malnourished infants remains to be determined (15). Also, whether the malnourished infant with enteritis can tolerate early refeeding is unknown (15).

We established a model of protein-energy malnutrition in suckling infant rabbits and used it to demonstrate that nutrient deprivation reduces small intestinal mass, impairs mucosal growth, delays maturation and enhances ileal glucose-stimulated $\mathrm{Na}^{+}$transport (16-18). Subsequent research demonstrated that the intestinal injury suffered by the malnourished infant infected with an enteric pathogen is more severe and more prolonged compared to that sustained by infected dietary controls (17). We have also shown that a brief period of refeeding of the noninfected-malnourished infant triggers rapid recovery of small intestinal growth, development, structure, and function (19). The present study was undertaken to assess the role of prompt intensive nutritional intervention in promoting small intestinal recovery from the mucosal damage induced by an acute enteritis in infant rabbits subjected to chronic postnatal protein-energy malnutrition.

\section{MATERIALS AND METHODS}

Experimental design. Does and litters of New Zealand White rabbits were quarantined at $4 \mathrm{~d}$ postpartum and observed for 3 $\mathrm{d}$ to ensure appropriate feeding behavior and good health. All animal experimentation was approved by the University of Calgary Animal Care Committee in accordance with guidelines established by the Canadian Council on Animal Care. Proteinenergy malnutrition was induced in the experimental group by combining two litters at $7 \mathrm{~d}$ of age to increase litter size to 13 to 16 kits (16). To ensure maternal health and prevent access to solid food, does were alternated at 24-h intervals. Does caged with pups had access to water only. Control litters were derived by combining two litters then reducing litter size to six to eight animals. These does and kits were permitted access to rabbit feed throughout the study. All kits were allowed free access to water for the duration of the study. On d 17, after an 18-h fast, selected litters from both dietary groups were infected by orogastric intubation with Yersinia enterocolitica strain MCH $700 \mathrm{~S}$ (serotype 0:3), originally isolated from a patient with diarrhea (20). Kits were infected with $10^{9}$ organisms suspended in $1 \mathrm{~mL}$ of $10 \% \mathrm{NaHCO}_{3}$ solution. Noninfected kits from both dietary groups also underwent the 18 -h fast. These manipulations resulted in four groups: noninfected and infected rabbits receiving 
the control diet and noninfected and infected nutrient-deprived rabbits (Fig. 1). To define the impact of malnutrition and the enteritis on intestinal structure and function, randomly selected kits from each group were killed on $\mathrm{d} 23$ of life, $6 \mathrm{~d}$ postinfection at the height of the illness. On $d 24$, randomly selected noninfected or infected malnourished litters were reduced in size to six pups to allow increased nutrient intake or nutritional rehabilitation. These kits were allowed to consume breast milk and rabbit feed ad libitum. On d 31 or $14 \mathrm{~d}$ postinfection, the "convalescent" phase, six groups of animals were studied: noninfected and infected dietary controls; noninfected and infected malnourished animals; and noninfected and infected malnourished groups who had undergone nutritional rehabilitation for 7 d from d 24 to 31 (Fig. 1).

Before infection, animals were weighed every $3 \mathrm{~d}$; after infection, weight gain, clinical status, and presence of diarrhea were assessed daily. On the day of study, blood was collected for measurement of total protein and kits were killed by an intracardiac injection of pentabarbitol sodium $(65 \mathrm{mg} / \mathrm{kg})$.

The small intestine from the ligament of Treitz to the most proximal attachment of the mesoappendix was removed and unstretched segments were measured. A 12-cm segment of ileum ending at the mesoappendix was removed, flushed with cold isotonic saline, and used for studies of $\mathrm{Na}^{+}$transport and electrical activity. Two additional $12-\mathrm{cm}$ segments were removed: a proximal segment beginning at the ligament of Treitz and a distal segment just proximal to the segment used for transport studies. These latter segments were flushed and weighed; a 2-cm segment was removed for morphology studies and mucosa was scraped from the remaining $10 \mathrm{~cm}$, weighed, homogenized in $2.5 \mathrm{mM}$ EDTA $(100 \mathrm{mg} / \mathrm{mL})$ at $\mathrm{pH} 7.4$ and frozen at $-80^{\circ} \mathrm{C}$ for later estimation of mucosal enzyme activities, protein, and DNA content. Swabs obtained from the jejunum and ileum of both noninfected and infected animals were plated onto SalmonellaShigella media.

Mucosal morphology. Tissue for light microscopy was fixed in $4 \%$ phosphate-buffered formalin, dehydrated, imbedded in paraffin wax, sectioned, and stained with hemotoxylin and eosin. Coded sections were examined by one observer without prior identification of the section. Villus height and crypt death were

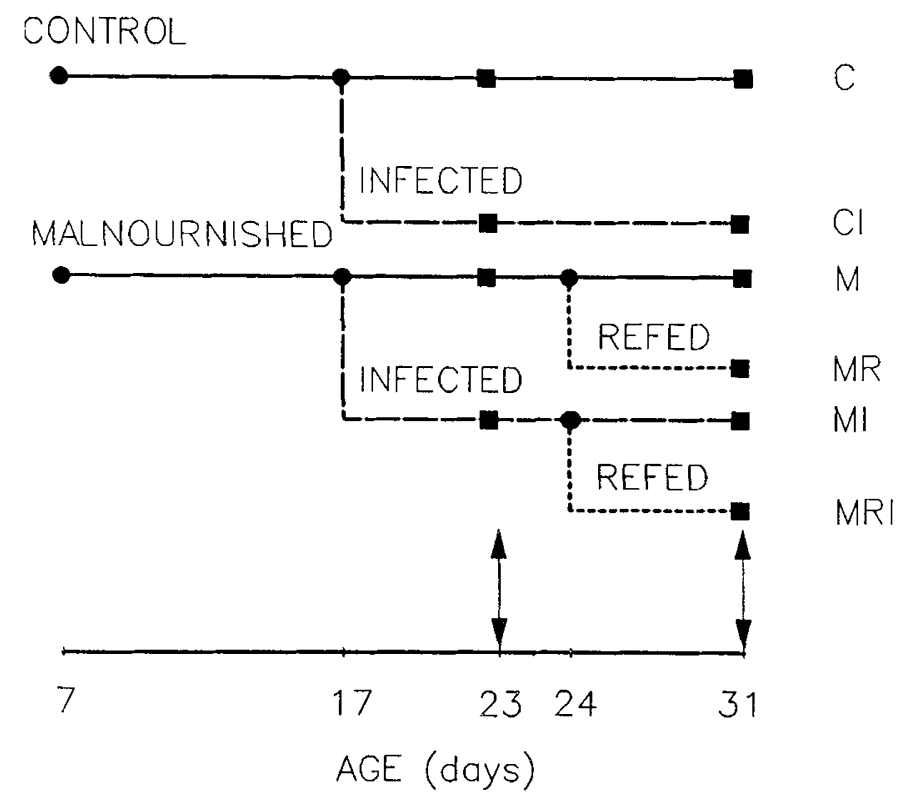

Fig. 1. Flow diagram depicting the ages of dietary manipulation; nfection with $Y$. enterocolitica on d 17; and study (double arrows and D) for each dietary group where applicable. On the far right are the iymbols used for each group: control $(C)$, control-infected $(C I)$, mallourished $(M)$, malnourished-refed $(M R)$, malnourished-infected $(M I)$, nalnourished-refed-infected $(M R I)$. measured in $10-12$ properly oriented crypt-villus units per segment using a calibrated micrometer.

Mucosal enzyme activities. Homogenates were assayed for sucrase and lactase activities by the method of Dahlqvist (21) and Na-K-ATPase activity by the method of Kelly et al. (22), and all results were expressed as $\mathrm{U} \cdot \mathrm{cm}^{-1}$. Protein content was measured by the method of Lowry et al. (23) and DNA content by the method of Hinegardner (24) using thymus DNA (Sigma Chemical Co., St. Louis, MO) as a standard.

Ileal transport and electrical activities. For ion transport studies, the mucosa of the distal segment was stripped of its overlying muscle and serosa and four adjacent segments were mounted in short-circuited Ussing chambers, exposing a $0.4-\mathrm{cm}^{2}$ surface area to $10 \mathrm{~mL}$ of oxygenated Krebs-bicarbonate buffer at $37^{\circ} \mathrm{C}$ and $\mathrm{pH} 6.4 \pm 0.1(25)$. Glucose $(10 \mathrm{mM})$ was added to the serosal side and mannitol $(10 \mathrm{mM})$ to the mucosal side. Ten $\mu \mathrm{Ci}^{22} \mathrm{Na}$ (New England Nuclear, Montreal, Quebec, Canada) was added to either the mucosal or serosal side of each tissue segment. The spontaneous transepithelial PD was determined and the tissue clamped at zero voltage by continuously introducing an appropriate $\mathrm{I}_{\mathrm{sc}}$ with an automatic voltage clamp (DVC 1000; World Precision Instruments, New Haven, CT), except for 15-20 s every 5 min when open PD was measured. Conductance was calculated from PD and $I_{s c}$ according to Ohm's law (26). After a 15-min equilibration period, samples for $\mathrm{Na}^{+}$fluxes were obtained from the mucosal and serosal chambers at 5-min intervals for 15 min. Immediately after completion of the basal period, glucose with or without mannitol (final concentration $30 \mathrm{mM}$ glucose and $10 \mathrm{mM}$ mannitol) was added to both sides of the tissue and after 15 min of equilibration, flux measurements were repeated. Tissue pairs were discarded if conductances varied by more than $30 \%$. Steady state unidrectional $J_{m s}, J_{s m}$, and $J_{\text {ne1 }} \mathrm{Na}^{+}$ fluxes $\left(\mu \mathrm{Eq} \cdot \mathrm{cm}^{-1} \cdot \mathrm{h}^{-1}\right)$ were calculated in paired tissues in the absence of an electrochemical gradient across the tissue by measuring three consecutive 5-min fluxes and one overall 15-min flux during each of the two periods.

Data are expressed as mean \pm SEM and statistical comparisons were made using one-way analysis of variance. Mortality data were analyzed by the $\chi^{2}$ method.

\section{RESULTS}

Clinical results. The number of animals studied for each group is shown in Figure 2. Initial mean body weight for the dietary groups did not differ on $\mathrm{d} 7$ when litters were combined (control $136 \pm 6 \mathrm{~g}$, malnourished $134 \pm 6 \mathrm{~g}$, malnourished-refed $138 \pm$ $4 \mathrm{~g}$ ). On $\mathrm{d} 16$, the day before the infection of randomly selected litters with $Y$. enterocolitica, the mean body weight of both the malnourished group $(206 \pm 5 \mathrm{~g})$ and the group of malnourished animals that would later be refed $(208 \pm 7 \mathrm{~g})$ was significantly less $(p<0.01)$ than that of dietary controls $(287 \pm 7 \mathrm{~g})$. The weight of the kits to be infected and the noninfected kits within each respective dietary group did not differ. On d 23 and 31, the noninfected and infected malnourished animals weighed significantly less than dietary controls (Fig. 2). However, on d 31 after $7 \mathrm{~d}$ of refeeding, both the infected and the noninfected malnourished-refed groups weighed significantly more than the groups subjected to ongoing malnutrition (Fig. 2). The mean body weight of the noninfected-malnourished-refed group, which had recovered to the level of dietary controls, was significantly greater than that of the infected-malnourished-refed group $(p<0.001)$.

Most of the infected rabbits developed a mild diarrheal illness lasting 2-3 d, which began 4-6 d after infection. However, five infected-malnourished animals developed severe persistent diarrhea and subsequent dehydration and died between 5 and $10 \mathrm{~d}$ after infection. Mortality was significantly greater $(p<0.05)$ in this group than in the infected dietary control or the infectedmalnourished-refed groups. Data on the animals that died are not included in the analyses summarized below. When the intestine was examined at the "acute phase" of the illness on $d$ 


\section{BODY WEIGHT}

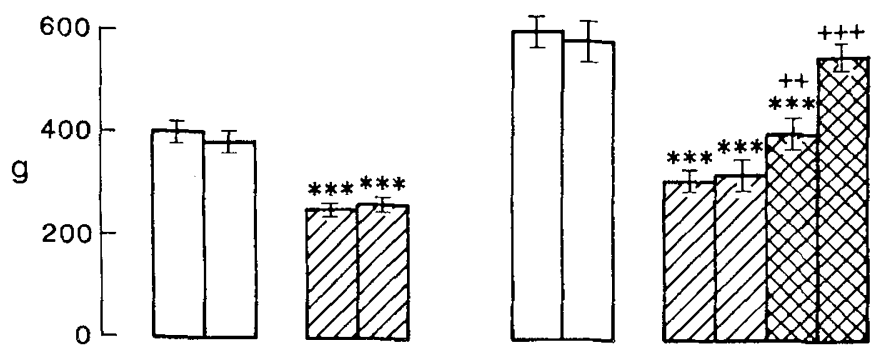

SMALL INTESTINAL WEIGHT
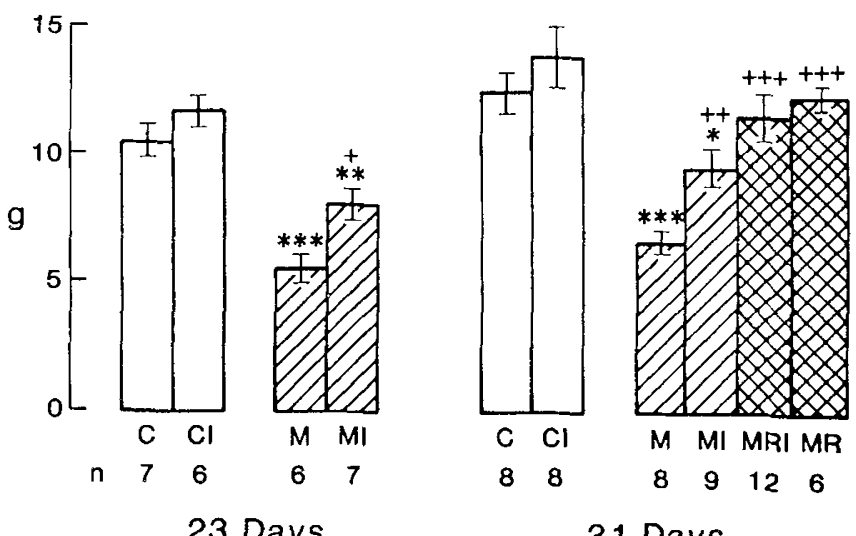

31 Days

Fig. 2. Mean body and total small intestine $w t(g)$ of noninfected and infected (I) controls $(C, \square])$, malnourished $(M, \mathbb{C})$ and malnourishedrefed $(M R$, rabbits at age in days, where $n$ is the number of animals $\left({ }^{*} p<0.05,{ }^{* *} p<0.01,{ }^{* *} p<0.001\right.$ comparing CI, M, MI, MRI, or MR to $\mathrm{C} ;+p<0.05,++p<0.01,+++p<0.001$ comparing MI, MRI, or $M R$ to $M$ ).

23, all infected animals in both dietary groups demonstrated evidence of a fluid-filled intestine. Subserosal abscesses were present throughout the small intestine and cecum, with the heaviest concentration in the distal ileum. On d 23 in the infected controls, five of six jejunal and all ileal cultures were positive for $Y$. enterocolitica; in the infected-malnourished group, six of seven jejunal and all ileal cultures were positive. On d 31 in infected animals, jejunal cultures from three of eight control, six of nine malnourished, and 10 of 12 malnourished-refed animals and all ileal cultures were positive. No enteric pathogens were cultured and no diarrhea was observed in noninfected animals of any dietary group. Serum total proteins did not differ between dietary groups at either age (data not shown).

Mucosal morphology (Fig. 3). Malnutrition alone significantly decreased crypt-villus lengths in both jejunum and ileum at 23 and $31 \mathrm{~d}$ of age compared to dietary controls. Infection of malnourished animals caused a further significant decrease in villus height and an increase in ileal crypt depth on $\mathrm{d} 23$ or $6 \mathrm{~d}$ postinfection. This was accompanied by an inflammatory infiltrate and numerous microabscesses that contained an abundance of polymorphonuclear leukocytes. Provision of $7 \mathrm{~d}$ of nutritional rehabilitation to 31-d-old infected-malnourished animals stimulated repair of the injured mucosa. Jejunal and ileal villus heights in the infected-malnourished-refed group did not differ from dietary controls and were significantly greater compared to those of the noninfected-malnourished animals. Crypt depths of both segments remained elongated and mild inflammation was observed in only two of 12 jejunal or ileal segments. In contrast to the recovery observed in the 31 -d-old infected-malnourishedrefed group, significant jejunal and ileal villus blunting and crypt elongation persisted in the 31 -d-old infected animals subjected

to ongoing malnutrition. This was associated with the ongoing presence of a severe inflammatory infiltrate and microabscesses.

In control diet animals examined 6 d postinfection on $\mathrm{d} 23$, jejunal villus blunting and jejunal and ileal crypt lengthening, as well as a striking inflammatory infiltrate in both segments, were observed. As with the infected-malnourished-refed group, the jejunal and ileal injury had completely recovered and inflammation had resolved in the 31-d-old infected controls. In the noninfected-malnourished group that was refed for $7 \mathrm{~d}$, villus length and crypt depth recovered to levels similar to those of dietary controls at $31 \mathrm{~d}$ of age and were significantly longer than those of animals subjected to ongoing malnutrition. No intestinal inflammation was noted in the noninfected animals of the three dietary groups.

Intestinal weight, protein, and DNA content. Total small intestine weight was significantly decreased in the noninfected and infected malnourished groups compared to dietary controls (Fig. 2 ). In the infected-malnourished group, small intestine weight was greater than in the noninfected-malnourished group, but remained less than that of 23-and 31-d-old dietary controls. In 31-d-old noninfected and infected malnourished animals that had been refed, small intestine weight recovered to that of dietary controls and was significantly elevated compared to the noninfected-malnourished group. Total small intestine weight did not differ between infected and noninfected dietary controls at either time period. The mucosal weight of jejunal and ileal segments paralleled total small intestine weight (data not shown).

Malnutrition alone significantly decreased mucosal protein and DNA content in the ileum compared to dietary controls on d 23 and 31 (Fig. 4). In the infected-malnourished animals, ileal mucosal protein at both ages and ileal mucosal DNA at $23 \mathrm{~d}$ were significantly less than dietary controls. Seven d of nutritional rehabilitation provided to 31 -d-old infected-malnourished animals initiated a complete recovery of ileal mucosal protein and DNA content to the level of dietary controls.

In infected dietary controls at 23 and $31 \mathrm{~d}$ of age, ileal mucosal protein and DNA content remained similar to that of noninfected dietary controls (Fig. 4). The 7-d refeeding period of noninfected-malnourished animals also initiated a complete recovery of ileal mucosal protein and DNA content to the level of dietary controls. Mucosal protein and DNA content in the jejunum did not differ from ileal data for each repetitive dietary group (data not shown).

Mucosal enzyme activities (Fig. 5). Malnutrition by itself caused a significant decline in ileal sucrase at $\mathrm{d} 31$ and $\mathrm{Na}-\mathrm{K}$ ATPase activities at both ages compared to noninfected dietary controls. Infection of malnourished animals triggered a further decrease in ileal lactase at $6 \mathrm{~d}$ postinfection. Nutritional rehabilitation of the 31-d-old infected-malnourished animals stimulated recovery of Na-K-ATPase activity in the ileum to the level of dietary controls. Lactase activity recovered to the level of the noninfected-malnourished group, but both lactase and sucrase activities remained depressed compared to dietary controls. In contrast, by $14 \mathrm{~d}$ postinfection in the group subjected to persistent malnutrition, ileal lactase, sucrase, and Na-K-ATPase activities all remained depressed compared to dietary controls.

In infected animals receiving a normal diet, ileal lactase and sucrase activities were significantly depressed at $6(\mathrm{~d} 23)$ and 14 (d 31) d postinfection compared to noninfected controls. $\mathrm{Mu}-$ cosal Na-K-ATPase activities did not differ between noninfected and infected animals receiving a normal diet. Refeeding of 31-dold noninfected-rıalnourished kits stimulated recovery of ileal $\mathrm{Na}-\mathrm{K}-\mathrm{ATP}$ ase activity to dietary control levels. In addition, ileal sucrase activity was significantly increased in the noninfectedmalnourished-refed group compared to the group subjected to persistent malnutrition.

Jejunal enzyme activities paralleled those in the ileum for each study group with the exception of lactase activity, which remained significantly depressed $(p<0.01)$ at $31 \mathrm{~d}$ of age in both the malnourished-infected and the malnourished-infected-refed 

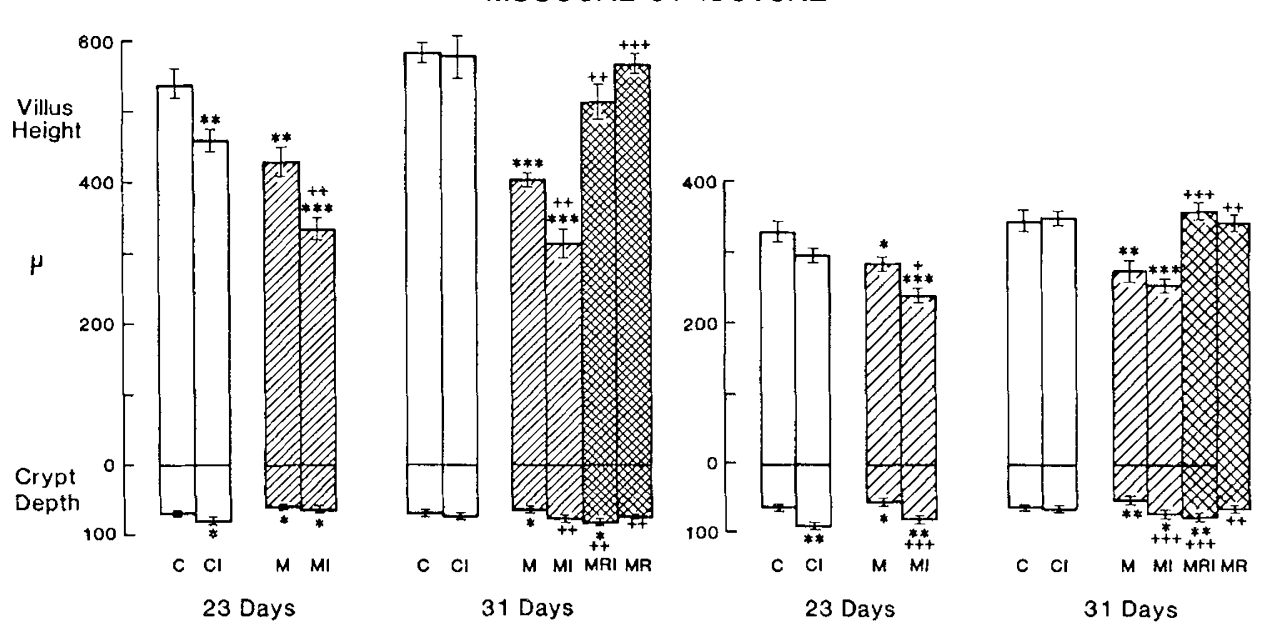

Fig. 3. Jejunal and ileal villus height and crypt depth in $\mu \mathrm{m}$. Abbreviations and symbols are the same as those used in Figure 2.

MUCOSAL PROTEIN
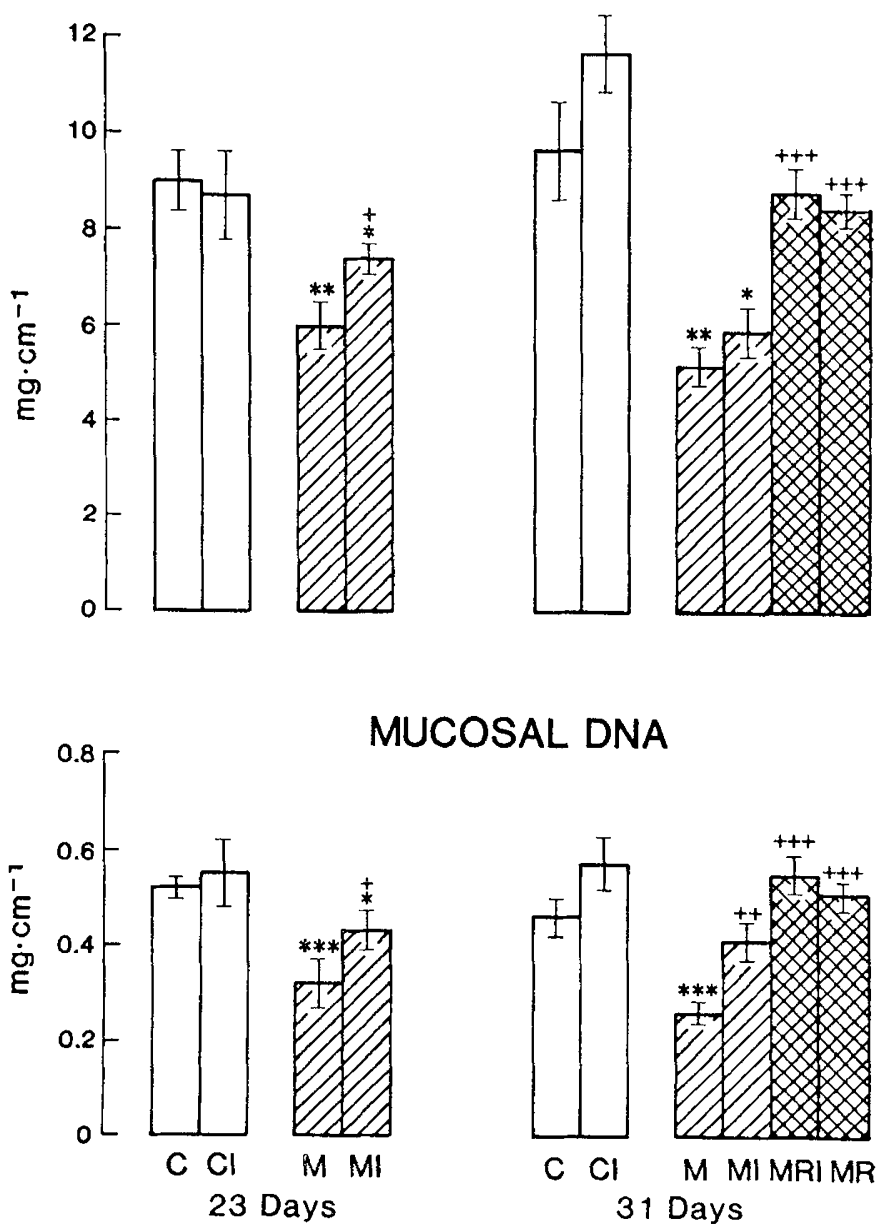

\section{MUCOSAL DNA}

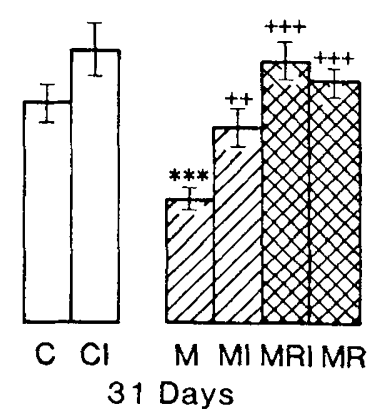

Fig. 4. Ileal segmental mucosal protein and DNA content in $\mathrm{mg}$. $\mathrm{m}^{-1}$. Abbreviations and symbols are the same as those used in Figure

,roups compared to the noninfected-malnourished and dietary ontrol groups (data not shown).

Ileal sodium transport and electrical activity. Table 1 summaizes unidrectional and net ileal $\mathrm{Na}^{+}$fluxes and electrical activity or each study group measured under basal conditions and after he addition of $30 \mathrm{mM}$ glucose. At both ages in all the nonin- fected dietary control, malnourished, and malnourished-refed groups, the addition of glucose significantly stimulated $\mathrm{J}_{\mathrm{ms}}, \mathrm{J}_{\text {net }}$, $\mathrm{I}_{\mathrm{sc}}$, and $\mathrm{PD}$ above basal levels. However, by d 31 in the noninfected-malnourished group, the increase in net $\mathrm{Na}^{+}$absorption $\left(\Delta \mathrm{J}_{\text {net }}\right)$ stimulated by the addition of glucose was significantly enhanced compared to the control and the malnourished-refed groups (Fig. 6).

In malnourished animals $6 \mathrm{~d}$ after infection, the response to glucose was blunted. On d 23, the addition of glucose failed to stimulate $J_{\mathrm{ms}}, \mathrm{J}_{\mathrm{net}}, \mathrm{I}_{\mathrm{sc}}$, and PD (Table 1) and $\Delta \mathrm{J}_{\text {net }}$ was significantly depressed (Fig. 6). Seven d of nutritional rehabilitation provided to 31-d-old infected-malnourished animals initiated complete recovery of glucose absorption as evidenced by significant increases in $J_{\mathrm{ms}}, J_{\text {net }}, I_{s c}, P D$, and $\Delta J_{\text {net. }}$. In contrast, in 31-d-old infected animals subjected to continued malnutrition, depression of glucose-stimulated $\mathrm{Na}^{+}$transport persisted. Glucose still did not stimulate $J_{m s}, J_{\text {net }}, I_{s c}, P D$, or $\Delta J_{\text {net }}$ in these malnourished animals that were 14 d postinfection.

In infected dietary controls $6 \mathrm{~d}$ after infection, the response to glucose was blunted in a similar manner to that observed in the infected-malnourished group. By d 31 in the infected dietary controls, glucose once again stimulated a significant increase in sodium absorption, as evidenced by increases in $\mathrm{J}_{\mathrm{ms}}, \mathrm{J}_{\text {net, }}, \mathrm{I}_{\mathrm{sc}}, \mathrm{PD}$, and $\Delta \mathrm{J}_{\text {net. }}$. This response was similar to that observed in the infected-malnourished-refed group.

\section{DISCUSSION}

In the developing infant, the intestine is immature and nutrient reserves are marginal. Thus, infants are especially susceptible to enteric damage caused by an acute infectious enteritis. One of the major concerns about providing nutritional rehabilitation to the malnourished infant during an acute diarrheal illness is that the severe intestinal damage caused by the enteritis and malnutrition will retard the digestion and absorption of the supplemental nutrients, especially carbohydrates (27). The maldigestion and malabsorption of sugars may cause an osmotic diarrhea that can further dehydrate the infant, impair nutrient absorption, and diminish the infant's chance for recovery. The purpose of our study was to determine how the injured intestine of the malnourished infant responds to the provision of supplemental nutrition introduced during the height of an acute enteric infection.

Kits were examined at $23 \mathrm{~d}$ of age to determine the extent of intestinal injury due to either malnutrition, acute enteritis, or both. The decreased nutrient intake caused by litter expansion induced profound protein-energy malnutrition. By d 23, the 

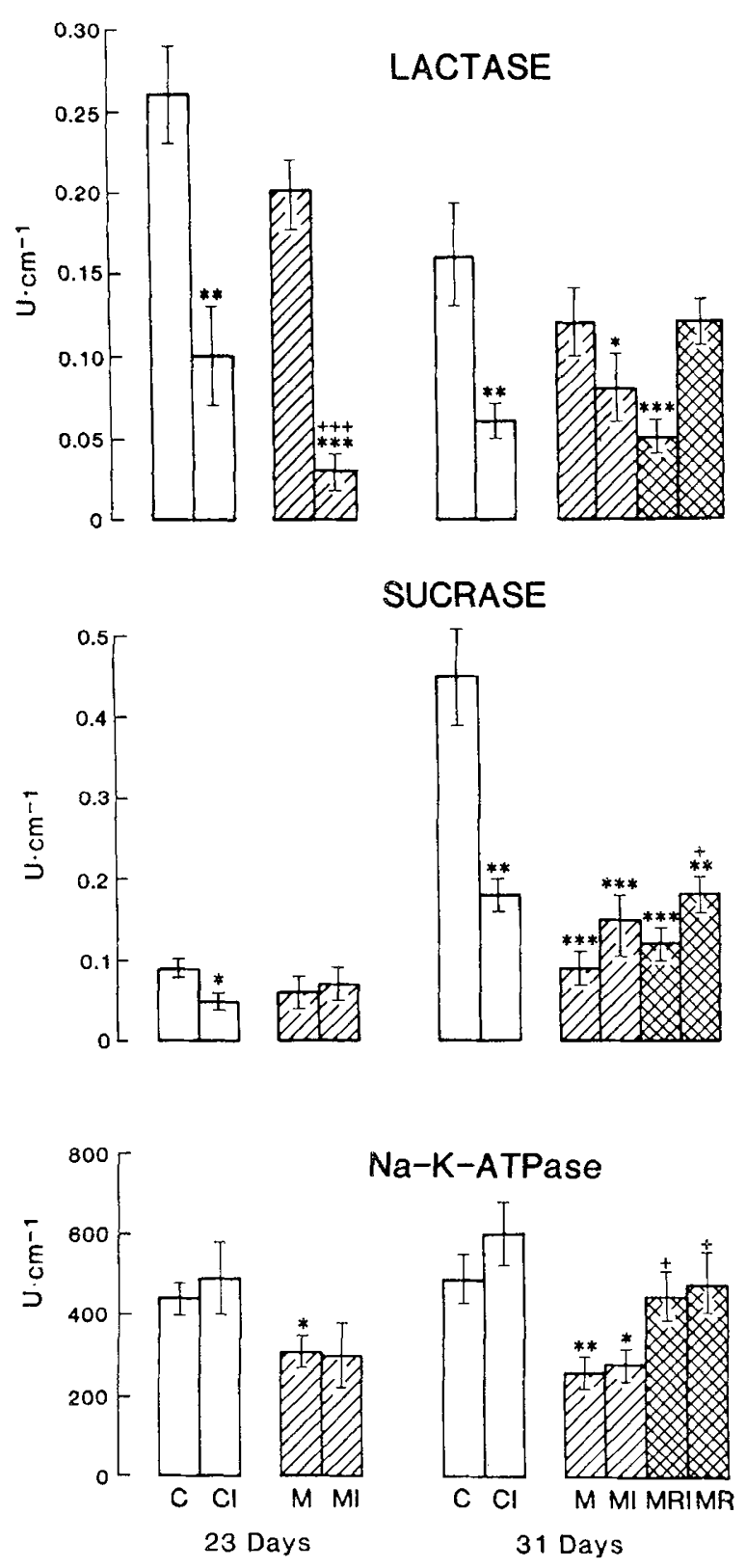

Fig. 5. Ileal mucosal lactase, sucrase, and Na-K-ATPase activities in $\mathrm{U} \cdot \mathrm{cm}^{-1}$. Abbreviations and symbols are the same as those used in Figure 2.

average weight of the malnourished animals was only $62 \%$ of dietary controls, corresponding to a state of moderate malnutrition (28). Although the noninfected-malnourished kits remained clinically well and enteric pathogen free, alterations in intestinal structure and function were noted. Mucosal Na-K-ATPase activity was decreased and mucosal mass was diminished, as evidenced by reduced total small intestinal weight, villus height, crypt depth, protein, and DNA content. Infants rabbits from both the malnourished and dietary control groups that were infected with $Y$. enterocolitica developed a diarrheal illness 4-5 $\mathrm{d}$ postinfection associated with positive intestinal cultures. On $\mathrm{d}$ 23 at the height of illness, infection caused severe intestinal damage in both dietary groups, as evidenced by alterations in mucosal structure, depressed mucosal disaccharidase activities, and the presence of an inflammatory infiltrate. In addition, glucose-stimulated $\mathrm{Na}^{+}$transport in the ileum was severely depressed.

By $14 \mathrm{~d}$ postinfection, the 31 -d-old infected dietary controls that were fed ad libitum throughout the illness exhibited nearly complete intestinal recovery from the injury. Crypt-villus length, mucosal protein, and DNA content returned to the levels of noninfected dietary controls, inflammation resolved, and there was recovery of glucose-stimulated $\mathrm{Na}^{+}$absorption. Only mucosal disaccharidase activities remained depressed. The delayed recovery of disaccharidase activity is a well-recognized phenomenon observed after acute enteric infections in infancy $(29,30)$. Clinically, despite the sustained depression of disaccharidase activities, body and intestinal growth were not retarded and kits were able to tolerate breast milk and rabbit feed without evidence of persistent diarrhea.

By $31 \mathrm{~d}$ of age, average body weight of the noninfectedmalnourished group had fallen to $51 \%$ of control values. This is indicative of severe malnutrition, defined as a body weight less than $60 \%$ of expected weight for age without edema (28). Intestinal mucosal mass remained depressed and mucosal function was further reduced in response to continued nutrient deprivation as evidenced by depressed segmental sucrase and $\mathrm{Na}-\mathrm{K}-$ ATPase activities. The 31-d-old nutrient-deprived infants that were $14 \mathrm{~d}$ postinfection with $Y$. enterocolitica demonstrated severe damage throughout the small intestine that was associated with persistent inflammation, structural damage, and reduced function. Mucosal disaccharidase activities and glucose-stimulated $\mathrm{Na}^{+}$absorption remained depressed. The continued depression of glucose-stimulated $\mathrm{Na}^{+}$transport would likely impede intestinal, glucose, $\mathrm{Na}^{+}$, and fluid absorption. This profound impairment of transport capacity probably contributed to the severe diarrhea and dehydration seen in the infected animals that died between 5 and $10 \mathrm{~d}$ postinfection. The apparent preservation of small intestine weight, mucosal protein, and DNA content despite a decrease in villus height is probably a reflection of the extensive inflammatory infiltrate. The preservation of mucosal Na-K-ATPase activity in the infected compared to the noninfected group also likely represents the presence of Na-K-ATPase activity in inflammatory cells infiltrating the mucosa rather than a preservation of activity in epithelial cells, as has been previously demonstrated in older $Y$. enterocolitca-infected rabbits (31). In summary, the infected-malnourished animals exhibited an increase in mortality and minimal evidence of intestinal recovery by $14 \mathrm{~d}$ postinfection.

In contrast, nutritional supplementation initiated during the acute diarrheal illness resulted in decreased mortality and rapid intestinal repair in previously malnourished infant rabbits. When infected-malnourished animals were provided with $7 \mathrm{~d}$ of nutritional rehabilitation that was initiated during the acute phase of the illness, no animals died, the diarrheal illness was not prolonged, and recovery was nearly complete. Although body weight did not recover to the level of dietary controls, small intestine weight did, which suggests that repair of the intestinal injury must occur before systemic repletion can take place. Nutritional rehabilitation was associated with recovery of crypt-villus structure and mucosal mass as well as resolution of the inflammatory infiltrate. In addition, mucosal Na-K-ATPase activity was increased compared to the malnourished group and there was a return of glucose-stimulated $\mathrm{Na}^{+}$transport to the level seen in the noninfected control and malnourished-refed groups. As with the infected dietary control and the infected-malnourished groups, only repair of segmental disaccharidase activities lagged behind the recovery of other parameters of intestinal function compared to the noninfected control groups. The lack of recovery observed in the infected animals subjected to ongoing malnutrition compared to the restoration of intestinal growth and function seen in the infected group that received supplemental nutrition cannot be attributed to differences observed during the acute stage of infection, because the degree of injury in the two groups did not differ when studied at $23 \mathrm{~d}$ of age. Although intestinal cultures for $Y$. enterocolotica remained positive in a similar number of infected kits from all dietary groups at $31 \mathrm{~d}$, we can not rule out the possibility of more persistent infection as op- 
Table 1. Sodium fluxes and electrical activities in short-circuited ileal epithelium*

\begin{tabular}{|c|c|c|c|c|c|c|c|}
\hline & & $J_{m s}$ & $\mathrm{~J}_{\mathrm{sm}}$ & $J_{\mathrm{nCt}}$ & $I_{\mathrm{sc}}$ & $\mathrm{PD}$ & G \\
\hline \multicolumn{8}{|l|}{$23 d$} \\
\hline \multirow[t]{2}{*}{ C } & Basal & $13.4 \pm 0.5$ & $14.0 \pm 0.4$ & $-0.6 \pm 0.6$ & $3.3 \pm 0.2$ & $-2.8 \pm 0.2$ & $32 \pm 1$ \\
\hline & Glucose & $15.4 \pm 0.6 \dagger$ & $13.1 \pm 0.6$ & $+2.3 \pm 0.7 \uparrow$ & $4.8 \pm 0.2 \hbar$ & $-3.7 \pm 0.2 \neq$ & $34 \pm 2$ \\
\hline \multirow[t]{2}{*}{$\mathrm{Cl}$} & Basal & $11.3 \pm 0.6$ & $10.9 \pm 0.3$ & $+0.4 \pm 0.4$ & $3.7 \pm 0.3$ & $-2.6 \pm 0.4$ & $27 \pm 2$ \\
\hline & Glucose & $13.0 \pm 0.9$ & $11.4 \pm 0.9$ & $+1.6 \pm 0.7$ & $3.9 \pm 0.3$ & $-2.6 \pm 0.3$ & $31 \pm 2$ \\
\hline \multirow[t]{2}{*}{ M } & Basal & $17.3 \pm 0.8$ & $17.1 \pm 0.8$ & $+0.2 \pm 0.7$ & $3.3 \pm 0.2$ & $-2.3 \pm 0.2$ & $46 \pm 3$ \\
\hline & Glucose & $22.1 \pm 0.91$ & $17.0 \pm 0.8$ & $+5.0 \pm 0.5 \S$ & $5.7 \pm 0.4 \S$ & $-3.7 \pm 0.3 \%$ & $51 \pm 3$ \\
\hline \multirow[t]{2}{*}{ MI } & Basal & $14.5 \pm 0.8$ & $15.2 \pm 1.0$ & $-0.7 \pm 0.4$ & $2.8 \pm 0.3$ & $-2.3 \pm 0.2$ & $33 \pm 2$ \\
\hline & Glucose & $16.3 \pm 0.8$ & $16.2 \pm 0.7$ & $+0.1 \pm 0.8$ & $3.4 \pm 0.3$ & $-2.6 \pm 0.3$ & $36 \pm 3$ \\
\hline \multicolumn{8}{|l|}{$31 \mathrm{~d}$} \\
\hline \multirow[t]{2}{*}{$\mathrm{C}$} & Basal & $12.8 \pm 0.8$ & $13.9 \pm 0.8$ & $-0.1 \pm 0.3$ & $3.6 \pm 0.2$ & $-2.8 \pm 0.2$ & $27 \pm 1$ \\
\hline & Glucose & $18.1 \pm 0.7 \$$ & $14.9 \pm 0.7$ & $+3.2 \pm 0.8 \pm$ & $5.5 \pm 0.3 \$$ & $-3.6 \pm 0.2 \dagger$ & $31 \pm 2$ \\
\hline \multirow[t]{2}{*}{$\mathrm{CI}$} & Basal & $11.5 \pm 0.7$ & $12.0 \pm 0.8$ & $-0.5 \pm 0.5$ & $3.1 \pm 0.2$ & $-2.4 \pm 0.4$ & $30 \pm 2$ \\
\hline & Glucose & $14.5 \pm 0.9 \dagger$ & $11.8 \pm 0.8$ & $+2.7 \pm 0.6 \pm$ & $4.6 \pm 0.2 \$$ & $-3.5 \pm 0.3 \div$ & $31 \pm 2$ \\
\hline \multirow[t]{2}{*}{ M } & Basal & $14.4 \pm 0.8$ & $15.2 \pm 0.7$ & $-0.8 \pm 0.2$ & $3.4 \pm 0.2$ & $-3.4 \pm 0.2$ & $41 \pm 2$ \\
\hline & Glucose & $20.6 \pm 0.9 \$$ & $16.3 \pm 0.6$ & $+4.3 \pm 0.8 \S$ & $5.8 \pm 0.4 \$$ & $-4.5 \pm 0.3 \%$ & $46 \pm 2$ \\
\hline \multirow[t]{2}{*}{ MI } & Basal & $17.8 \pm 0.5^{\prime \prime}$ & $18.1 \pm 0.5$ & $-0.3 \pm 0.6$ & $3.6 \pm 0.3$ & $-2.8 \pm 0.3$ & $38 \pm 3$ \\
\hline & Glucose & $19.9 \pm 0.9$ & $19.8 \pm 0.7$ & $+0.1 \pm 0.8$ & $3.7 \pm 0.3$ & $-3.3 \pm 0.2$ & $44 \pm 3$ \\
\hline \multirow[t]{2}{*}{ MR } & Basal & $15.0 \pm 0.7$ & $15.2 \pm 0.8$ & $-0.2 \pm 0.6$ & $3.3 \pm 0.3$ & $-2.8 \pm 0.3$ & $37 \pm 2$ \\
\hline & Glucose & $19.2 \pm 0.8 \neq$ & $16.3 \pm 0.8$ & $+2.9 \pm 0.5$ & $5.1 \pm 0.3 *$ & $-3.8 \pm 0.3 t$ & $42 \pm 3$ \\
\hline \multirow[t]{2}{*}{ MRI } & Basal & $11.8 \pm 0.4$ & $12.1 \pm 0.4$ & $-0.3 \pm 0.3$ & $3.8 \pm 0.2$ & $-3.2 \pm 0.2$ & $33 \pm 1$ \\
\hline & Glucose & $15.2 \pm 0.8 \$$ & $11.8 \pm 0.6$ & $+3.4 \pm 0.5 \S$ & $4.6 \pm 0.2 \ddagger$ & $-4.0 \pm 0.2 \dagger$ & $34 \pm 2$ \\
\hline
\end{tabular}

$*$ Values are mean \pm SEM for noninfected and infected (I) dietary controls $(C)$, malnourished $(M)$, and malnourished-refed (MR) groups. $J_{m} . J_{m}$, $J_{\mathrm{nc}}$, and $\boldsymbol{l}_{\mathrm{sc}}$ are in $\mu \mathrm{Eq} \cdot \mathrm{cm}^{-2} \cdot \mathrm{h}^{-1}$; PD is in $\mathrm{mV}$; and $\mathrm{G}$ (tissue conductance) is in $\mathrm{mS} \cdot \mathrm{cm}^{-2}$.

$\dagger p<0.05$, basal period $v s$ glucose-stimulated period.

$\ddagger p<0.01$, basal period $u$ s glucose-stimulated period.

$\S p<0.001$, basal period vs glucose-stimulated period.
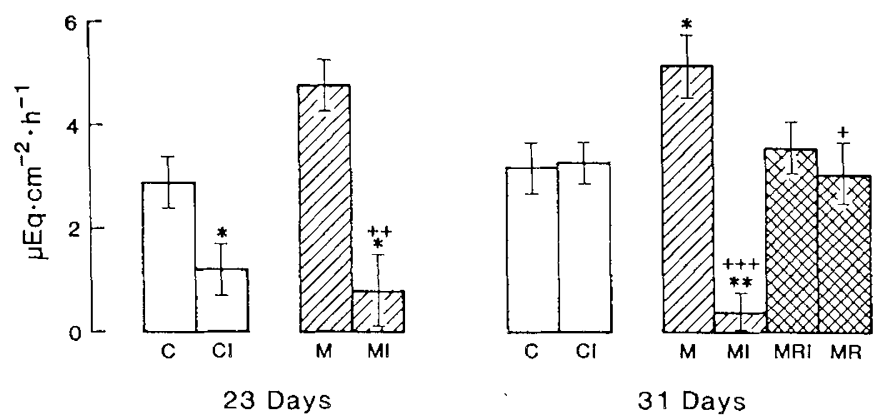

Fig. 6. Increment of ileal $\mathrm{Na}^{+}$absorption above basal levels after the addition of $30 \mathrm{mM}$ glucose $\left(\Delta \mathrm{J}_{m \in t}\right)$ in $\mu \mathrm{Eq} \cdot \mathrm{cm}^{-2} \cdot \mathrm{h}^{-1}$. Abbreviations and symbols are the same as those used in Figure 2.

posed to persistent colonization in the infected-malnourished group.

Several factors may be responsible for the decreased mortality and enhanced intestinal repair observed in infected-malnourished animals that received nutrient supplementation compared to infected animals subjected to ongoing malnutrition. Extra energy provided in the form of increased quantities of breast milk and rabbit feed presumably plays an important role in the intestinal recovery associated with the refeeding process, as shown in slightly older noninfected rabbits that were refed with feed alone (19). The presence of growth factors such as epidermal growth factor and the immune components, including maternal Ig and lymphoid cells, all known to be present in breast milk, also may have contributed to intestinal recovery from the bacterial enteritis. To what extent each of these components contributed to the restoration process after an acute enteric infection remains to be determined.

In summary, our study demonstrates that early nutritional rehabilitation of the malnourished infant rabbit subjected to an acute enteritis is well tolerated, improves overall nutritional status, and enhances intestinal repair. Our work provides experimental evidence in support of the establishment of clinical trials designed to provide early refeeding for malnourished infants suffering from acute enteric infections.

Acknowledgments. The authors thank P. Brockway, D. Philpott, and $\mathrm{K}$. van der Lee for expert technical assistance, as well as C. Brooks and G. Hardy for care devoted to the preparation of the manuscript.

\section{REFERENCES}

1. Palmer DL, Koster FT, Alam AK, Islam MR 1976 Nutritional status: determinant of severity of diarrhea in patients with cholera. J Infect Dis $134: 8-14$

2. Tomkins A 1981 Nutritional status and severity of diarrhoea among preschool children in rural Nigeria. Lancet 1:860-862

3. Black RE, Brown $\mathrm{KH}$ Becker $\mathrm{S} 1984$ Malnutrition is a determining factor in diarrheal duration. but not incidence among young children in a longitudinal study in rural Bangladesh. Am J Clin Nutr 39:87-94

4. Chung AW. Viscorova B 1948 The effect of early oral refeeding versus early oral starvation on the course of infantile diarrhea. $J$ Pediatr 33:14-22

5. Rees L. Brook CGD 1979 Gradual reintroduction of full-strength milk after acute gastroenteritis in children. Lancet 1:770-771

6. Dugdale A. Lovell S. Gibbs V. Ball D 1982 Refeeding after acute gastroenteritis: a controlled study. Arch Dis Child 57:76-78

7. Molla A. Molla AM, Rahim A. Sarker SA. Mozaffar Z, Rahamar M 1982 Intake and absorption of nutrients in children with cholera and rotavirus infection during acute diarrhea and after recovery. Nutr Res 2:233-242

8. Isolauri E. Vesikari T 1985 Oral rehydration, rapid feeding and cholcstyramino for treatment of acute diarrhea. J Pediatr Gastroenterol Nutr 4:366-374

9. Santosham M. Foster S, Reid R. Bertrando R. Yolken R. Burns B. Sack RB 1985 Role of soy-based. lactose-free formula during treatment of acute diarrhea. Pediatrics 76:292-298

10. Khin MU. Nyunt-Nyunt-Wai. Myo-Khin, Mu-Mu-Khin. Tin U. Thane-Ioe 1985 Effect on clinical outcome of breast feeding during acute diarrhoca. $\mathrm{Br}$ Med J 290:587-589

11. Isolauri E. Vesikari T, Saba P. Viander M 1986 Milk versus no milk in rapid refecding after acutc gastroenteritis. J Pediatr Gastroenterol Nutr 5:254-261

12. Brown KH, Gastanaduy AS, Saavedra JM, Lembeke J. Rivas D. Robertson AD. Yolken R. Sack RB 1988 Effect of continued oral feeding on clinical and nutritional outcomes of acute diarrhea in children. J Peciatr 112:191200

13. Santosham M. Fayad IM. Hashem M. Gocpp JG. Refat M. Sack RB 1990) A comparison of rice-based oral rehydration solution and "early feeding." for the treatment of acute diarrhea in infants. J Pediatr 1 16:868-875

14. Bennish MI. A7ad AK. Rahman O. Phillips RE 1990 Hypoglyeemia during diarrhea in childhood: prevalence, pathophysiology, and outcome. N F.ngl J Med 322:1357-1363 
15. Ulshen MH 1988 Refeeding during recovery from acute diarrhea. J Pediatr 112:239-240

16. Butzner JD, Gall DG 1988 Impact of protein-calorie malnutrition on the developing intestine. Biol Neonate 54:151-159

17. Butzner JD, Gall DG 1988 Effects of chronic protein-calorie malnutrition on small intestinal repair after an acute bacterial enteritis: a study in infant rabbits. Pediatr Res 23:408-413

18. Butzner JD, Brockway PD, Meddings JB 1990 Effects of malnutrition on microvillus membrane glucose transport and physical properties. Am J Physiol 259:G940-G946

19. Butzner JD, Gall DG 1990 Impact of refeeding on intestinal development and function in infant rabbits subjected to protein-energy malnutrition. Pediatr Res 27:245-251

20. Pai CH, Mors V, Seemayer IA 1980 Experimental Yersinia enterocolotica enteritis in rabbits. Infect Immun 28:238-244

21. Dalqvist A 1968 Assay of intestinal disaccharidases. Anal Biochem 22:99-107

22. Kelly M, Butler DG, Hamilton JR 1972 Transmissible gastroenteritis in piglets: a model of infantile viral diarrhea. J Pediatr 80:925-931

23. Lowry OH, Rosebrough NJ, Farr AL, Randall RJ 1951 Protein measurement with the Folin phenol reagent. J Biol Chem 193:265-275
24. Hinegardner R 1971 An improved fluorometric assay for DAN. Anal Biochem 39:197-201

25. Shepherd R, Hamilton JR, Gall DG 1980 The postnatal development of sodium transport in the proximal small intestine of the rabbit. Pediatr Res 14:250-253

26. Clarkson TW, Toole SR 1964 Measurement of short-circuit current and ion transport across the ileum. Am J Physiol 206:658-668

27. Lifschitz $\mathrm{CH}$, Shulman RJ 1990 Nutrition therapy for infants with diarrhea. Nutr Rev 48:329-338

28. Torun B, Viteri FF 1988 Protein-energy malnutrition. In: Shils ME, Young UR (eds) Modern Nutrition in Health and Disease. Lea \& Febiger, Philadelphia, pp 746-773

29. Lifshitz F, Coello-Ramirez P, Gutierrez-Topete G, Cornado-Cornet MC 1971 Carbohydrate intolerance in infants with diarrhea. J Pediatr 79:760-767

30. Kumar V, Chandrasekaran R, Bhaskar R 1977 Carbohydrate intolerance associated with acute gastroenteritis: a prospective study of 90 well-nourished Indian infants. Clin Pediatr (Phila) 16:1123-1127

31. O'Loughlin EV, Humphreys G, Dunn I, Kelly J, Lian CJ, Pai C, Gall DG 1986 Clinical, morphological, and biochemical alterations in acute intestinal yersiniosis. Pediatr Res 20:602-608 